\title{
Prescribing Pattern of Gliclazide, Metformin and Combination Therapy with Insulin in UAE
}

\author{
Sabrina Ait Gacem*, Zainab Tehami, Maryam Mazrouai, Mohamed Shamssain \\ College of Pharmacy \& Health Sciences, Ajman University, Ajman, UAE.
}

\section{ARTICLE INFO \\ Article history: \\ Received on: 26/03/2018 \\ Accepted on: 04/06/2018 \\ Available online: 29/06/2018}

\section{Key words:}

Diabetes mellitus, Insulin,

Metformin, Gliclazide.

ABSTRACT
Diabetes Mellitus (DM) is characterized by the inability of the body to process sugar. Glycemic control is important
in the management of diabetic patients; therefore, there is a particular concern towards the insufficient management
of oral drug therapy and delayed insulin therapy initiation. The current study was made to observe the status of anti-
diabetic drugs' prescription pattern. This is a cross-sectional, questionnaire-based survey study, which was conducted
over a period of February 2014 to May 2014 and it was carried out in Ajman. A convenient sample comprising a
total of (213) diabetic participants of 18 years old and above. A self-administered bilingual questionnaire was used
as a tool to collect data and the results were analyzed using Microsoft Excel. The prescribing trend was found to
be monotherapy ( $43 \%$ Metformin, $33 \%$ Insulin and $17 \%$ Gliclazide) and ( $7 \%$ ) of participants used a combination
therapy of Metformin and Insulin. The study reflected that the prescribing trend in the enrolled participants was mainly
monotherapy and among the cardiovascular complications reported that can cause major threat was hypertension.
Similar other studies indicate that the compliance with medication, exercise and avoiding risk factors are very
important to prevent complications.

\section{INTRODUCTION}

Diabetes is a chronic disease presented by the inability of the body to process sugar and it is a major cause of morbidity and mortality (Alberti and Zimmet, 1998; Afolayan and Sunmonu, 2010). In the long term, uncontrolled Diabetes Mellitus leads to organ damage and is associated with microvascular and macrovascular complications (Stumvoll et al., 2005). There are many cardiovascular complications that can cause a major threat and one of them is smoking which is associated with an increased risk of progression of chronic diabetes-related complications (Huda et al., 2010). Glycemic control is very important in the management of diabetic patients and more effective methods to help patients follow medical regimens are needed. The management and initiation of some antidiabetic drugs are of a particular concern that's why this study is a component of a medical audit that evaluates the prescribing practice of the prescribers through

\section{${ }^{*}$ Corresponding Author}

Sabrina Ait Gacem, College of Pharmacy \& Health Sciences, Ajman

University, Ajman, UAE.

E-mail: sabrinaaitgacem@yahoo.com patients' feedback and the current study was designed to observe the current status of the anti-diabetic drugs prescription pattern.

\section{MATERIAL AND METHODS}

This is a cross-sectional survey based study which had been conducted over a period of three months from February 2014 to May 2014 and it was carried out in Ajman, UAE.

A convenient sample was used comprising a total of (213) participants from different nationalities and Participants with diabetes (Type I or Type II), 18 years old and above, regardless of their income or educational level. A self-administered bilingual questionnaire was used as a tool to collect data from the participants. It was distributed to participants matching with the specified inclusion criteria in waiting rooms in some clinics and patient's visiting community pharmacies.

\section{Inclusion and exclusion criteria}

Diabetic patients from different nationalities; 18 years old and above regardless of their income or educational level in waiting rooms of some clinics and patients visiting community pharmacies. Participants willing to participate and understand 
English or Arabic and also must be a resident of Ajman only. Language barrier and participants from other emirates were not enrolled in this study.

Table 1: Demographic characteristics of enrolled participants.

\begin{tabular}{ccc}
\hline Variable $(\mathbf{n}=\mathbf{2 1 3})$ & Frequency & Percentage (\%) \\
\hline \multirow{2}{*}{ Gender } & Female: 120 & $56 \%$ \\
& Male: 93 & $44 \%$ \\
\hline \multirow{2}{*}{ Nationality } & Arabs: 96 & $45 \%$ \\
& Locals: 81 & $38 \%$ \\
\hline \multirow{2}{*}{ Educational Level } & Others: 36 & $17 \%$ \\
\hline \multirow{2}{*}{ Marital Status } & University: 136 & $64 \%$ \\
& High school: 47 & $22 \%$ \\
& Not Educated: 30 & $14 \%$ \\
\hline
\end{tabular}

The results show that most of the participants were Arabs (45\%) \& the majority were educated $(64 \%)$ holding a university degree, $(22 \%)$ a High School degree and most of them were non-married (75\%).

Table 2: Participants lifestyle and Health Characteristics.

\begin{tabular}{|c|c|c|}
\hline Variable $(n=213)$ & Frequency & Percentage (\%) \\
\hline \multicolumn{3}{|l|}{ Smoking } \\
\hline Male & Yes: 76, No: 17 & Yes: $82 \%$, No: $18 \%$ \\
\hline Female & Yes: 4, No: 116 & Yes: $3 \%$, No: $97 \%$ \\
\hline Exercising & Yes: 53, No: 160 & Yes: $25 \%$, No: $75 \%$ \\
\hline \multicolumn{3}{|l|}{ Duration of DM } \\
\hline \multirow{4}{*}{ All Participants } & Less than 5 years: 75 & Less than 5 years: $35.21 \%$ \\
\hline & 5 to 10 years: 80 & 5 to 10 years: $37.56 \%$ \\
\hline & More than 10 years: 58 & More than 10 years: $27.23 \%$ \\
\hline & Less than 5 years: 40 & Less than 5 years: $43 \%$ \\
\hline \multirow[t]{3}{*}{ Male } & 5 to 10 years: 26 & 5 to 10 years: $28 \%$ \\
\hline & More than 10 years: 27 & More than 10 years: $29 \%$ \\
\hline & Less than 5 years: 35 & Less than 5 years: $29 \%$ \\
\hline \multirow[t]{2}{*}{ Female } & 5 to 10 years: 54 & 5 to 10 years: $45 \%$ \\
\hline & More than 10 years: 31 & More than 10 years: $26 \%$ \\
\hline \multicolumn{3}{|c|}{ Presence of Hypertension } \\
\hline All Participants & Yes: 64, No: 149 & Yes: $30.04 \%$, No: $69.96 \%$ \\
\hline Male & Yes: 27, No: 66 & Yes: $29 \%$, No: $71 \%$ \\
\hline Female & Yes: 37, No: 83 & Yes: $31 \%$, No: $69 \%$ \\
\hline
\end{tabular}

The results show that ( $82 \%)$ of Male participants were smokers compared to only ( $3 \%)$ of female participants, also only $(25 \%)$ of the participants were exercising, The majority of male participants (43\%) had DM for a duration less than 5 years while the majority of females $(45 \%)$ had it for 5 to 10 years, (31\%) of females had hypertension along with DM compared to (29\%) male.

\section{Pre-testing and validation of the questionnaire}

Prior to the study, the questionnaire was validated by subject experts for its content and relevance. Furthermore, it was field-tested on a pilot sample of 50 participants to clarify any ambiguities and to determine the reliability of the questionnaire.

\section{Ethical considerations}

Prior to the administration of the questionnaires, the intentions of the survey were explained and participants were encouraged to participate without any undue pressure. Participation was voluntary and all respondents joined in with no incentives and signed the informed consents to take part in this study. The study was approved by the institutional ethics committee.

Table 3: Anti-diabetic agents in Monotherapy and Combination therapy.

\begin{tabular}{lcc}
\hline Treatment & Frequency $(\mathbf{n}=\mathbf{2 1 3})$ & Percentage (\%) \\
\hline Monotherapy & 91 & \\
Metformin & 71 & $43 \%$ \\
Insulin & 37 & $33 \%$ \\
Gliclazide & & $17 \%$ \\
\hline Combination Therapy & 14 & $7 \%$ \\
\hline Insulin + Metformin & 14 & \\
\hline
\end{tabular}

The results show that the prescribing trend of monotherapy was ( $43 \%$ Metformin, 33\% Insulin and 17\% Gliclazide) while combination therapy of insulin and Metformin represented only (7\%).

\section{Statistical analysis}

The results were analyzed using Microsoft Excel. Descriptive statistics were used to summarize the data concerning the demographic characteristics. Categorical variables (such as nationality and educational level) were described by using frequency, percentages, bar chart and pie chart.

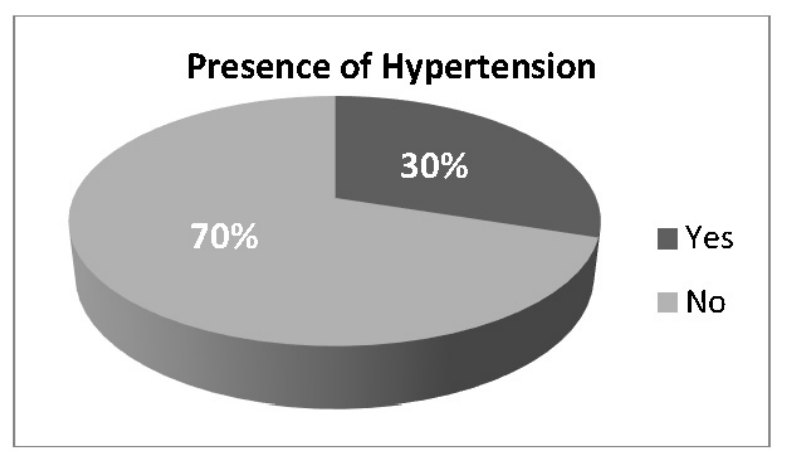

Fig. 1: Presence of hypertension for all Participants (Male and Female). The results show that $(30 \%)$ of participants had hypertension besides DM.

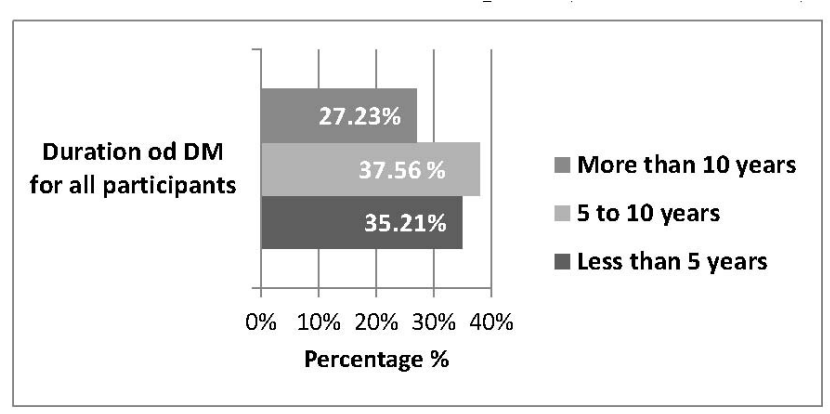

Fig. 2: Duration of DM for all Participants (Male and Female). The results show that the majority of participants $(37.56 \%)$ had DM for 5-10 years followed by $(35.21 \%)$ who had it for less than 5 years and $(27.23 \%)$ for more than 10 years. 


\section{RESULTS AND DISCUSSION}

The results show that the majority of participants (37.56\%) had DM for 5-10 years followed by (35.21\%) who had it for less than 5 years and $(27.23 \%)$ for more than 10 years. In the current study, most of male participants $(43 \%)$ were observed to have less than 5 years duration of diabetes compared to $(29 \%)$ of female respondents, while most of the female respondents $(45 \%)$ reported a duration of diabetes from 5 to 10 years compared to (28\%) of males (Table 2) (Figure 2). Among the Cardiovascular complications which can cause major threat, (30\%) of the respondents reported the presence of hypertension as well and $(82 \%)$ of male respondents were smokers compared to $(3 \%)$ in females (Figure 1).

It was observed in the current study that only $(25 \%)$ of respondents followed their physician's daily exercise advice which is significantly higher than a study conducted in Egypt in 2010 in which nearly $0 \%$ followed daily exercise advices (Ibrahim et al., 2010). In contrast a study conducted in Nepal in 2013 showed a higher response in which about 50\% followed physicians' daily exercise advices (Parajuli et al., 2014). In the current study, the prescribing trend was found to be monotherapy, $43 \%$ Metformin, 33\% Insulin and 17\% Gliclazide (Table 3). The most commonly used antidiabetic drug (monotherapy) was Metformin in the present study. Metformin has beneficial effects on several cardiovascular risk factors and therefore it's widely regarded as the drug of choice for most patients with diabetes (Krentz et al., 2005). This result was in line with other studies which had similar observations such as (Sultana et al., 2010; Yurgin et al., 2007). This result contrasts the reports of some other studies done in India (Xavier et al., 1999; Lau et al., 1996) which reported that Glibenclamide was the most commonly prescribed anti-diabetic drug. If the glycaemic targets can't be achieved with maximum doses of Oral Antidiabetic Drugs (OADs) as in the traditional management therapy, the American Diabetes Association (ADA) recommended the initiation of insulin therapy for the treatment of type II diabetes if the target HbAlc of (7\%) is not achieved within three months treatment with Metformin along with lifestyle interventions (Nathan et al., 2009).

In the present study (33\%) have used Insulin as monotherapy which is much higher than a previously reported study $(11.5 \%)$ in New Delhi, India (Sultana et al., 2010). This could be due to presence of some comorbid conditions such as hypertension, etc. or due to uncontrolled diabetes and resistance to oral antidiabetic drugs. Starting intensive insulin therapy early in the course of type II diabetes or immediately after a diet and exercise regimen failure is supported by many studies in order to protect the remaining $\beta$-cell function and improve the glycaemic control (Campbell and White, 2002).

It was also observed that (7\%) of the study participants used a combination therapy of Metformin and Insulin. It is known that the effectiveness of insulin either as monotherapy or in combination with OAD is well established. A treatment with a combination of insulin and metformin alone proved more costeffective than triple OAD therapy of sulfonylurea, metformin, and thiazolidinedione (Fonseca, 2006).

\section{CONCLUSION}

The study reflected that the prescribing trend in the enrolled participants was found to be mainly monotherapy and among the cardiovascular complications reported that can cause major threat was hypertension. Similar other studies indicate that the compliance with medication, exercise and avoiding risk factors are very important to prevent complications.

\section{CONFLICT OF INTERESTS}

The authors declare no conflicts of interest.

\section{ACKNOWLEDGMENT}

The authors acknowledge the valuable help and guidance provided by Dr. Fetta Djessas during this research and the assistance of Miss Elaf.

\section{REFERENCES}

Afolayan AJ, Sunmonu TO. In vivo studies on anti-diabetic plants used in South African herbal medicine. J Clin Biochem Nutr, 2010; 47:98-106.

Alberti KG, Zimmet PZ. Definition, diagnosis and classification of diabetes mellitus and its complications. Part 1: diagnosis and classification of diabetes mellitus provisional report of a WHO consultation. Diabet Med, 1998; 15:539-553.

Campbell K, White JR. Insulin Therapy in Type 2 Diabetes. J Am Pharm Assoc, 2002; 42:602-611.

Fonseca V. The role of insulin therapy with type 2 diabetes mellitus. Insulin, 2006; 1:51-60.

Huda A, Haider F, Hazim A. The effect of smoking on some micro vascular complications. Diabetes, 2010; 17:132-136.

Ibrahim NK, Attia SG, Sallam SA, Fetohy EM, El-Sewi F. Physicians' therapeutic practice and compliance of diabetic patients attending rural primary health care units in Alexandria. J Family Community Med, 2010; 17:121-8.

Krentz AJ, Bailey CJ. Oral antidiabetic agents: current role in type II diabetes mellitus. Drugs, 2005; 65:385-411.

Lau GSN, Chan JCN, Chu PLM, Tse DCK, Critchley JAJH. Use of antidiabetic and antihypertensive drugs in hospital and outpatient settings in Hong Kong. Ann Pharmacother, 1996; 30:232-7.

Nathan DM, Buse JB, Davidson MB, Ferrannini E. Medical management of hyperglycaemia in type 2 diabetes mellitus: a consensus algorithm for the initiation and adjustment of therapy: a consensus statement from the American Diabetes Association and the European Association for the Study of Diabetes. Diabetologia, 2009; 52:17-30.

Parajuli J, Saleh F, Thapa N, Ali L. Factors associated with nonadherence to diet and physical activity among Nepalese type 2 diabetes patients. BMC Res Notes, 2014; 7:758.

Stumvoll M, Goldstein BJ, Van Haeften TW. Type 2 diabetes: principles of pathogenesis and therapy. Lancet, 2005; 365:1333-1346.

Sultana G, Kapur P, Aqil M, Alam MS, Pillai KK. Drug utilization of oral hypoglycemic agents in a university teaching hospital in India. J Clin Pharm Ther, 2010; 35:267-77.

Xavier D, Nagarani MA, Srishyla MV. Drug utilization study of antihypertensives and antidiabetics in an Indian referral hospital. Indian $\mathrm{J}$ Pharmacol, 1999; 31:241-2.

Yurgin N, Secnik K, Lage MJ. Antidiabetic prescriptions and glycemic control in German patients with type 2 diabetes mellitus: a retrospective database study. Clin Ther, 2007; 29:316-25.

How to cite this article:

Gacem SA, Tehami Z, Mazrouai M, Shamssain M. Prescribing Pattern of Gliclazide, Metformin and Combination Therapy with Insulin in UAE. J App Pharm Sci, 2018; 8(06): 175-177. 